75 巻 755 号 $(2009-7)$

\title{
ボロン添加 $\mathrm{Al}-\mathrm{Mg}-\mathrm{Si}$ 合金の長時間高温保持による強度変化と $\mathrm{Mg}_{2} \mathrm{Si}$ 析出形態変化*
}

\author{
上路 林太郎*1, 槙 井 浩 一*2, 下 条 純*3 \\ 長尾 護 ${ }^{* 4}$, 赤松 博 史 ${ }^{* 3}$, 田中康 弘 ${ }^{* 5}$
}

\section{Morphology-Change of $\mathrm{Mg}_{2} \mathrm{Si}$ and Strength-Change in Boron-Added Al- $\mathrm{Mg}-\mathrm{Si}$ Alloys}

\author{
Rintaro UEJI ${ }^{* 6}$, Koichi MAKII, Jun SHIMOJO, \\ Mamoru NAGAO, Hiroshi AKAMATSU and Yasuhiro TANAKA \\ ${ }^{* 6}$ Department of Advanced Materials Science, Kagawa University, \\ 2217-20 Hayashi-cho, Takamatsu-shi, Kagawa, 761-0396 Japan
}

\begin{abstract}
Changes of the strength and the $\mathrm{Mg}_{2} \mathrm{Si}$ precipitates in Boron-added $\mathrm{Al}-\mathrm{Mg}^{-} \mathrm{Si}$ alloy, which is attempted to be used as casks in a nuclear power plant, during the long-time duration at the temperatures at $230^{\circ} \mathrm{C}$ or $250^{\circ} \mathrm{C}$ for $10000 \mathrm{hr}$ at maximum. $\beta^{\prime}-\mathrm{Mg}_{2} \mathrm{Si}$ with rod-like morphology was precipitated after the heat treated. The relationship between the strength and the Larson-Millar parameter (L. M. P.) is represented by liner function when the duration time is longer than $13 \mathrm{hr}$ $\left(230^{\circ} \mathrm{C}\right)$ or $11 \mathrm{hr}\left(250^{\circ} \mathrm{C}\right)$; whereas the relationship between the inverse square root of the mean diameter $\left(\mathrm{d}^{-0.5}\right)$ along long axis of the $\beta^{\prime}-\mathrm{Mg}_{2}$ Si precipitates and L. M. P. is also expressed by liner function. The strength change of the $\mathrm{B}^{-}$-added alloy is explained using the Ashby's theory concerning precipitation hardening, just similar as that of the $\mathrm{Al}-\mathrm{Mg}-\mathrm{Si}$ alloys without $\mathrm{B}$.
\end{abstract}

Key Words: Nonferrous Metal, Heat Treatments, Tensile Properties, Nuclear Materials

\section{1. 情}

原子力発電所加発生する使用済然料を貯藏する手段と して，キャスクと呼ばれる金属製の容器を利用する例が増 えつある゙、キャスク中て燃料集合体を仕切っているバス ケット用の材料には，除熟，未臨界維持機能，耐クリープ 特性のような長時閒の高温強度などが要求されている゚2.さ らに近年では，使用済然料をキャスクにより数十年間保管 する中間貯藏施設方計画されており，これらのキャスクの バスケット材には，除熱性能に優机，且つ，キャスク軽量 化のために，軽量金属の代表である $\mathrm{Al}$ 合金を使用する検討 がすすんでるる゙ ${ }^{(3)}$ またこの中間貯蔵キャスクのバスケッ

* 原稿受付 2009 年 1 月 5 日.

*1 正員, 香川大学工学部 (画761-0396 高松市林町 2217-20).

*2 (株) 神戸製鋼所技術開発本部研究企画部.

*3 (株) 神戸製鋼所機械エンジニアリングカンパニー高砂機器 工場

*4 (株) 神戸製鋼所技術開発本部材料研究所

*5 香川大学工学部

E-mail : ueji@eng.kagawa-u.ac.jp
卜材には，使用済然料の中間貯蔵後の輸送にも耐えられる 機械特性㴗求されている(4).

高強度 $\mathrm{Al}$ 合金の一つとして，化合物 $\mathrm{Mg}_{2} \mathrm{Si}$ の時效析出強 化を利用した 6000 系Al-Mg-Si 系合金がある. Al-Mg-Si 系 合金では，一度 $\mathrm{Mg}_{2} \mathrm{Si}$ が完全に固溶する高温に保持後, 室温 まで急冷して過䭂和な状態こしてから，MgSSi の析出が生じ る温度て時効して高強度化を達成している. Al 合金をバス ケット材に利用するにあたっては，中性子吸収能を有する ${ }^{10} \mathrm{~B}$ を分散させた Al一Mg-Si 系合金を利用することが検討さ れている(5).

一方で，バスケット材は㜣料の放出する熱により，貯蔵 開始時にはAl-Mg-Si 系合金の時效析出温度域こ近い高温に なり，その後，数十年の貯藏期間中に $100^{\circ}$ C程度まて温度が 低下してゆくことになる. 従来から,このようなアルミ合 金は，高温に一定保持された場合，過時効力泩じ強度低下 が生じることが知られている，そのため，Al-Mg-Si 系合金 をバスケット材として利用するためには，長時間の時効処 理中に生じる $\mathrm{Mg}_{2} \mathrm{Si}$ の析出挙動を十分に把握する必要があ る. 
これまでこ，屒尾らけ は を添加しないAl-Mg-Si 系合金 の過時効による強度変化と $\mathrm{Mg} 2 \mathrm{Si}$ の形態の変化を調查して おり，長時間熱処理によりもたらされる強度低下は， $\mathrm{Mg} 2 \mathrm{Si}$ のオストワルド成長による粗大化により説明できることを 明らかにしている. しかし， B 添加による, 長時間熱処理 による強度の変化や $\mathrm{Mg} S \mathrm{Si}$ の形態変化に及ぼす影響こつい ては明らかとなっていいそこで本研究では，キャスク を構成する材質として中性子の吸収に有効な B を添加した Al-MgSi 合金の高温長時間保持による強度変化と $\mathrm{Mg} 2 \mathrm{Si} の$ 形態変化を調查した

\section{2. 实的方法}

表 1 に示す組成を有するB 潞加Al-MgSi 采合金を溶 製鉡造した後，面削およひ压延により $10 \mathrm{~mm}$ 厚さの板とし

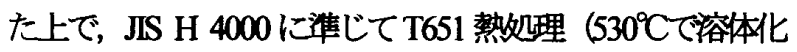
熱処理と水命却の後、塑生ひずみ 1.5 3.0\%までの引張癟正 を行なった上で $180^{\circ} \mathrm{C} \times 18 \mathrm{hr}$ の時效処理を行う処理をを施 した. その後, $230^{\circ} \mathrm{C}$ 2 $20^{\circ} \mathrm{C}$ 各温度にて, 種々の时間 (最 長 10000h）保持する時效熟処理を施した 得られた各種熱 処理材に対して, 強度特性と組織の評価を行った 強度特 性は，圧延方向に直角な力向が引張軸と平行となるように

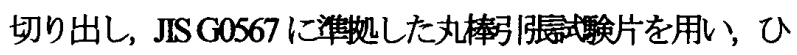

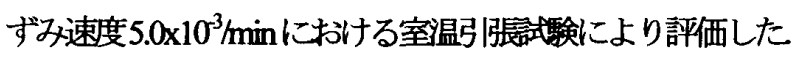
また, $\mathrm{Mg} 2 \mathrm{Si}$ の形態を評価するため, 透過型電子顕微鏡 (公 称加速電圧 $300 \mathrm{kV}$ ）による組織稓察を行った

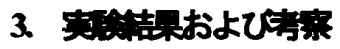

図1に各種条件の熱処理を施した B 添加材の 02\%耐 力(a)と引偯強さ(b)を示す. 異なる熱処理昷度と熱処理時間 を一の変数として整理する力法として, 次式(1)に示され るラーソン・ミラーパラメータ(LMP)を用いるカ㤼があ.

$$
\mathrm{LMP}=T(20+\log t)
$$

ここで，Tは熱処理昷痛単位，K]，tは熱処理時間 [単位， $\mathrm{hr}]$ である. LMPは，主に高温・長時間の熱処理により，析出 物がオストワルド成長を示す材料の強度と熱処理条件の関 係を考察する際に用いられる゙. 図 1に示すように、今回 得られた熱処理材の強度は，250年で最も LMP が小さいデ 一夕点，すなわち熱処理時間が最も短い $\left(250^{\circ} \mathrm{Cx} 2 \mathrm{hr}\right)$ デー 夕点を除けば，すへて温度，時間に関わらず，LMPの1次 関数として整理できることが明らかとなった. また, 図 1 (a)には、以前、長尾ら屴蕔告した B を含まない Al-Mg-Si 合金の0.2\%而力を示している. 同じLMPで比較した場合, $\mathrm{B}$ を含まない Al-Mg-Si 合金は, 40MPa 程度低い $0.2 \%$ 耐力 を示すものの, B 添咖と同様の傾きを有する直線で近以
することが出来る.この結果は， B 添加材の高温長時間熱 処理時の強度変化は， B を含まないAl-Mg-Si 合金と同梯の 組織変化に起因することを示唆している.

図 2 に溶体化熱処理後のB 添加才のTEM 明視野像と電 子線回折図形を示寸. 観察方向はく001>としており、明視野 像の水平方向と重直方向がともに $\diamond 001>$ と平行となってい

Table 1 Chemical composition of the sample (mass\%).

\begin{tabular}{|c|c|c|c|c|c|c|c|c|c|}
\hline $\mathrm{B}$ & $\mathrm{Si}$ & $\mathrm{Fe}$ & $\mathrm{Cu}$ & $\mathrm{Mn}$ & $\mathrm{Mg}$ & $\mathrm{Cr}$ & $\mathrm{Zn}$ & $\mathrm{Ti}$ & $\mathrm{Al}$ \\
\hline 1.03 & 0.73 & 0.40 & 0.27 & 0.04 & 1.00 & 0.23 & 0.11 & 0.02 & $\mathrm{Bal}$. \\
\hline
\end{tabular}
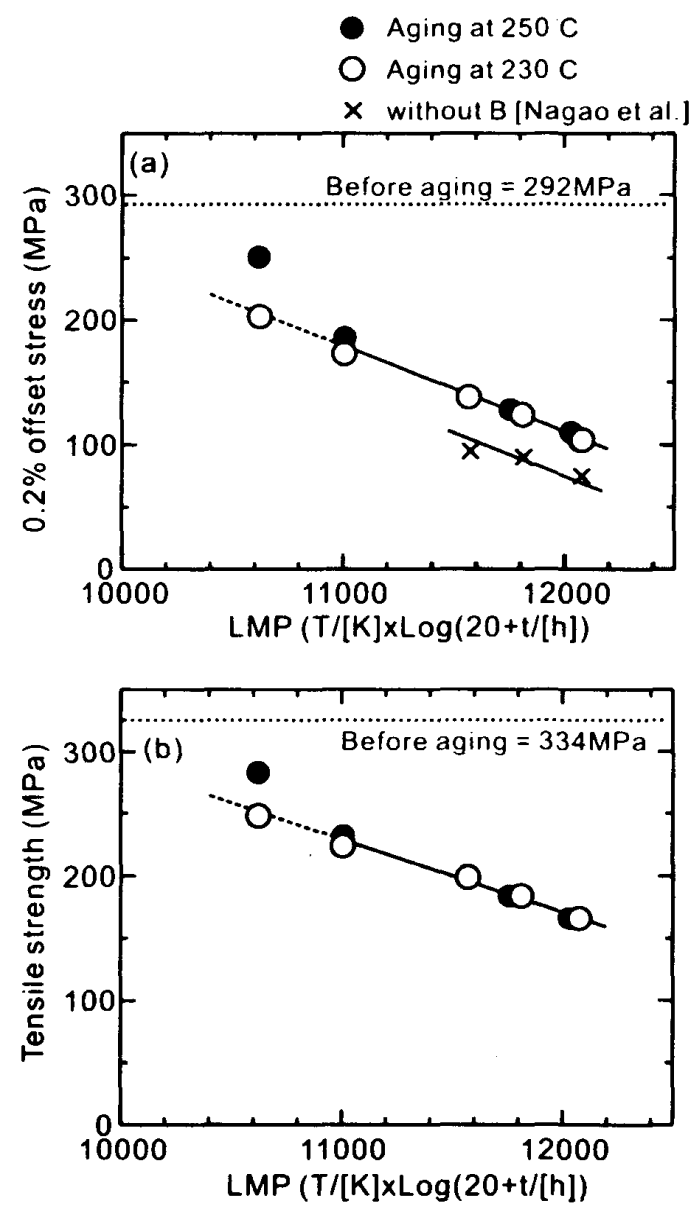

Fig. $1 \quad 0.2 \%$ offset stress and tensile strength of the Al-Mg-Si alloys heat treated at various conditions.

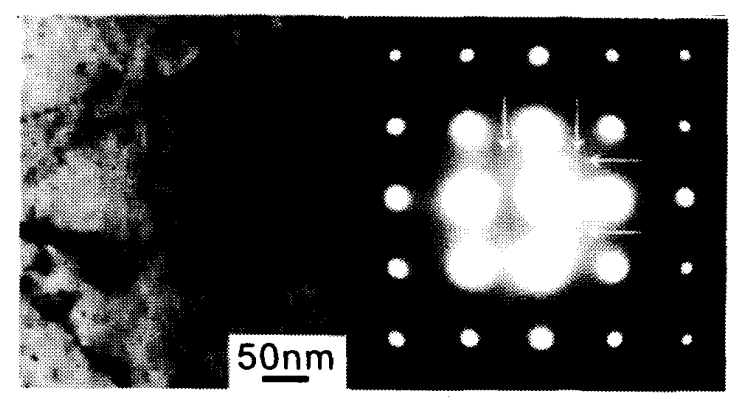

Fig. 2 Bright field image (left) and electron diffraction pattern (right) of the B-added Al-Mg-Si alloy after solution heat-treatment. 
る. 明視野像では，転位がわずが観察されるのに加えて， 直径数 $\mathrm{nm}$ 程度の非常に微細な析出物か観察される. 回折 像には、母相のA 1 \%[001]入射の回折パターンと線状の回 折パターンが認められた、同様の線状の回折パターンは 過去の研究けにおいても観察されており、析出物の伸長形狀 に起因するものであると考えられる。これらは, $\mathrm{MgSi}_{2}$ 析 出過程により生じる GPゾーンやQ相等票と考えられる.し かし， $\mathrm{Mg}_{2} \mathrm{Si}$ 析出の初期過程は現在,アトムプローブ影微 鏡や高分解能像観察により得られた新しい知見により，議 論されているところ(タ)であり，詳細は不明である.

図 3 は $230^{\circ} \mathrm{Cx} 13 \mathrm{hr}$ (LMP=10623)時効処理材(a)および $230^{\circ} \mathrm{Cx} 75 \mathrm{hr}$ (LMP=11006) 時効処理材(b)の明視野潒と電子 線回折図形である. 明視野像では，いずれの熱処理材でも，

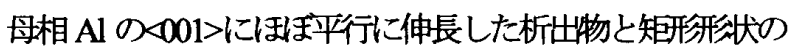

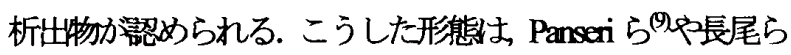
(のか蕔告している，棒状中間相及”-Mg2 $\mathrm{Si}$ の析出形態と良く一 致している. 才なわち, $\beta^{\prime}-\mathrm{Mg}_{2} \mathrm{Si}$ が，3つのく001>に平行に 伸び形成され，矩形形伏として観察される析出物棒状 及’-Mg2Si の長軸方向に垂直な䉼面であると考えることがで きる. 時效処理时間の増大とともに $\beta^{\prime}-\mathrm{Mg} 2 \mathrm{Si}$ の長さと断面 積が大きくなってゆく. 図 4 は, $250^{\circ} \mathrm{C} て ゙ 2 \mathrm{hr}$ (LMP=10620) から 3000hr (LMP=12282)までの各種侍間で时效处理を施し た試料の TEM 観察結果を示している. 図4の(b)および(d) で他のものでは観察できない強度の弱、回折スポットも認
められる。これらは $\beta^{\prime}-\mathrm{Mg} 2 \mathrm{Si}$ 以外の中間相がわずがて析

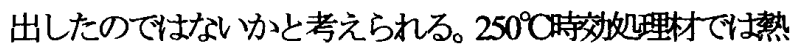

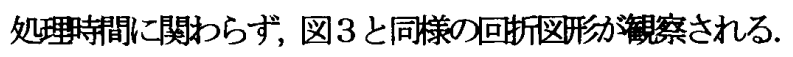
時效処理時間の増大に伴、析出物はく001>を伸長方向と平 行とする関係を保ちつつ大さが増大している.

図3およひ図4て観察された $\mathrm{MgSi}$ の断面直径を貺定 した結果を図5に示寸. 直径の値 $\mathrm{d}$ は， $\mathrm{Mg}_{2} \mathrm{Si}$ の伸長方向 に垂直な断面の長軸方向と短軸方向の平均值を用いた，ま
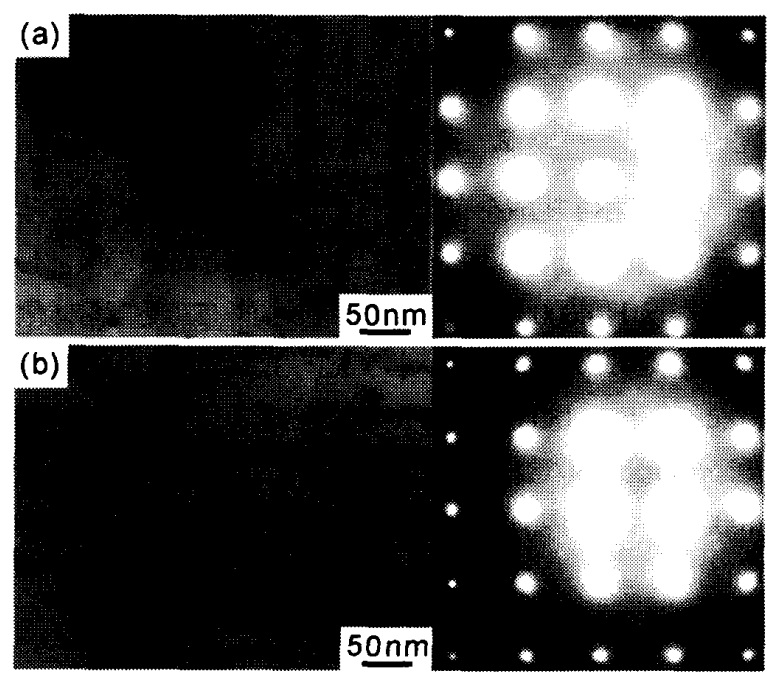

Fig. 3 Bright field images (left) and electron diffraction patterns (right) of the $\mathrm{B}$-added $\mathrm{Al}-\mathrm{Mg}-\mathrm{Si}$ alloy aging heat-treated at $230^{\circ} \mathrm{C}$ for $13 \mathrm{hr}$ (a) or $75 \mathrm{hr}$ (b).
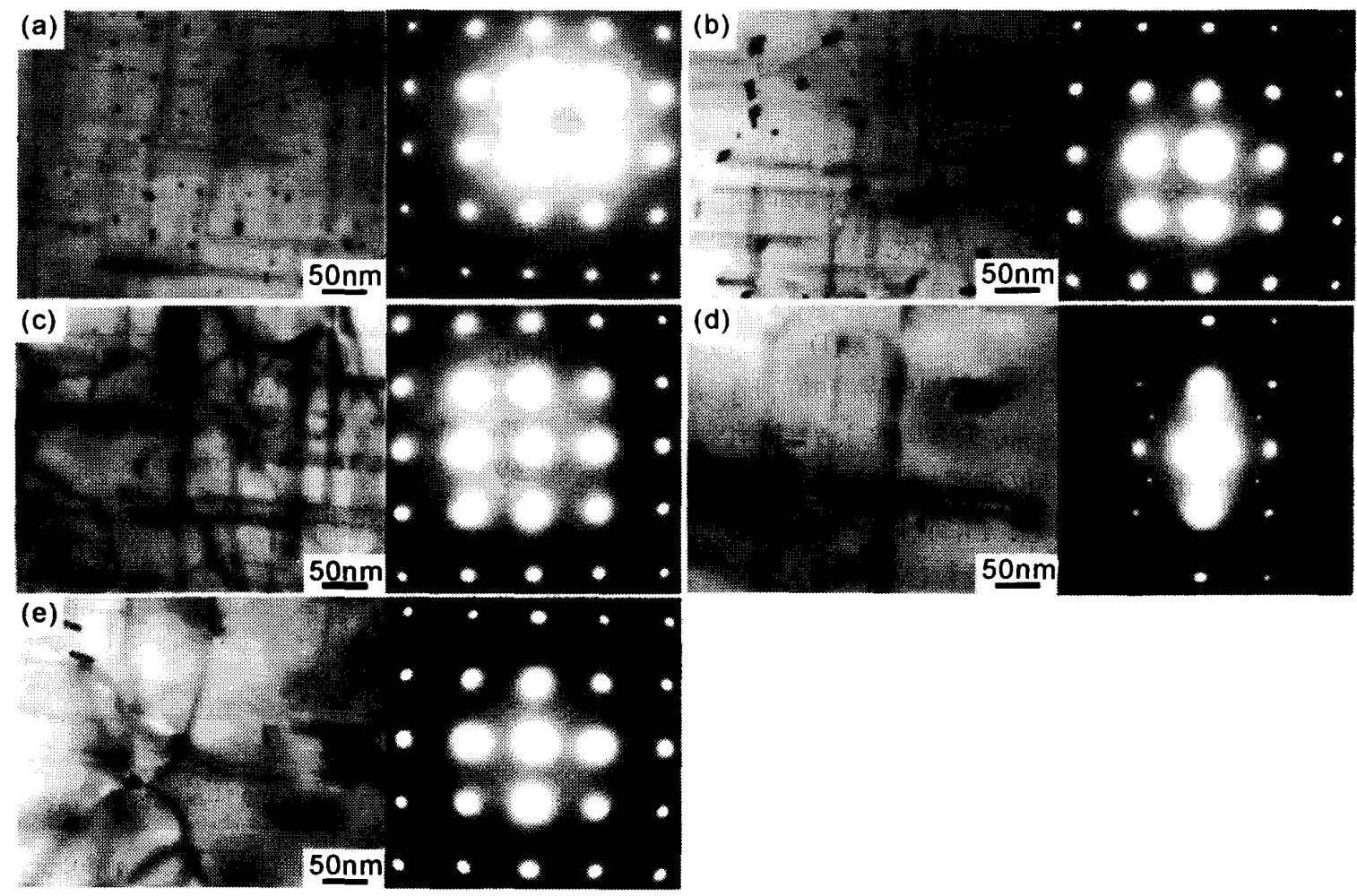

Fig. 4 Bright field images and electron diffraction patterns of the B-added $\mathrm{Al}-\mathrm{Mg}-\mathrm{Si}$ alloy heat treated at $250^{\circ} \mathrm{C}$ for $2 \mathrm{hr}$ (a), $11 \mathrm{hr}(\mathrm{b}), 300 \mathrm{hr}$ (c), $1000 \mathrm{hr}$ (d) or $3000 \mathrm{hr}$ (e). 
Aging at $250 \mathrm{C}$

$\mathrm{O}$ Aging at $230 \mathrm{C}$
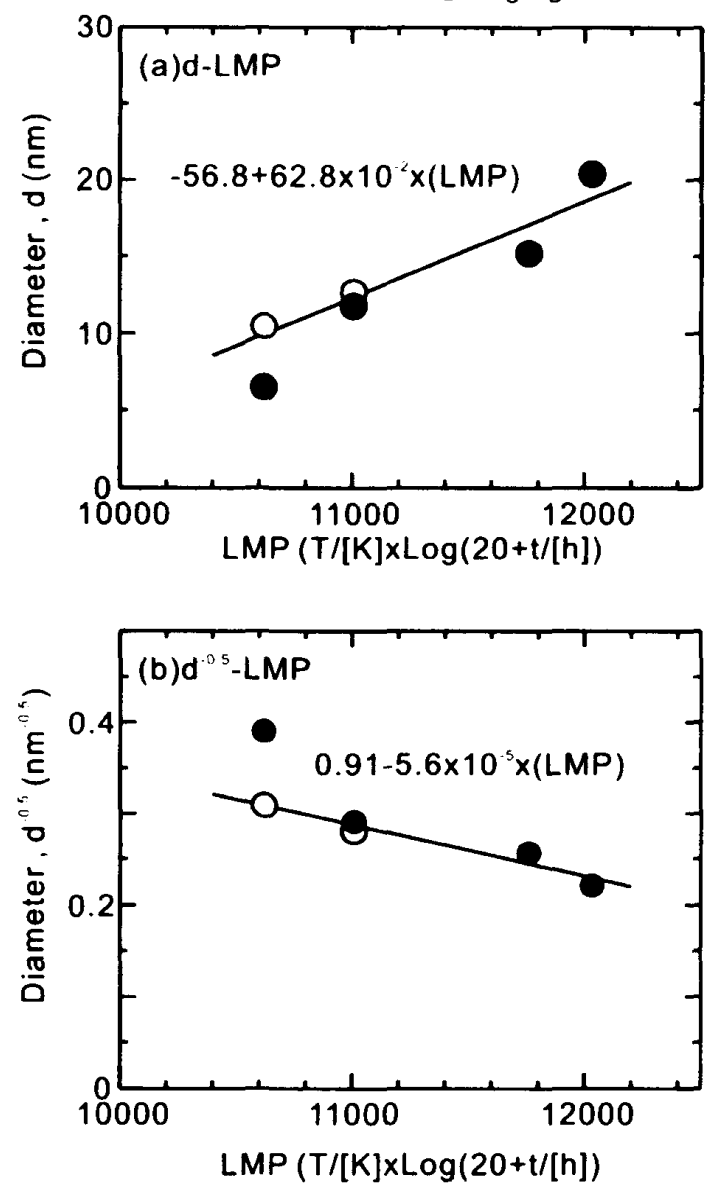

Fig. 5 Relationship between the mean diameter of $\mathrm{Mg}_{2} \mathrm{Si}$, $\mathrm{d}$ and L.M.P. d-L.M.P. (a) and d $^{0.5}$-L.M.P.(b).

た, 図5(a)はd と LMP の関係を、(b)ではd の0.5 乗と LMP の関係を示している. LMP の增大とともに すなわち時効 処理昷度が高いほど, あるいせ時効姏理時間が長いほど, $\mathrm{Mg} 2 \mathrm{Si}$ の直径は大きくなる. 直径と LMPの関倸は, (a)に示 した d の值そのままを用いる場合よりも，(b)に示した d $\mathrm{d}^{05}$ の值を用いた場合の方が，直線により精度良く近以できる ことが分かる. また， d と d 05 のずれの場合であっても， $250^{\circ} \mathrm{C}$ で最も短時間 (2hr) 時効処理を施した試料のデータ 点は他のデータ点の近似直線よりも大きく離れた值を示し ていた。この結果は，短時間の時效処理では， $\mathrm{Mg}_{2} \mathrm{Si}$ の形 態変化が，他の長時間材とは異なるメカニズムであること を示唆している.

以上のように，時效熱処理による B 添加材の強度と析出 物の大きさの変化は，短時間 $\left(250^{\circ} \mathrm{C} \times 2 \mathrm{hr}\right)$ 時効処理材を除 くと LMP により良く整理することが可能であることが本 研究により明らかとなった $\mathrm{MgSi}$ のように母相と比べて 硬く塑性变形しない分散粒子の強化は，Ashby の分散強化 理碖(10)を用いて議的侖することが出来る。直径 d の分散粒子 を有する多結晶体の場合、強度 $\sigma は$

$$
\sigma=\sigma_{0}+m C G \sqrt{\frac{b \gamma V}{2 d}}
$$

で示される。ここで

$\sigma_{0} \quad$ : 母相合金の強度 [MPa]

$m \quad:$ Tayor 因子 [-]

C : 実験定数 [-]

$G \quad$ :母相の剛性率 [MPa]

$V \quad$ : 分散粒子の体積率 [-]

$\gamma \quad$ : せん断ひずみ [-]

である.この式に従えば，時效処理中の析出物の形態変化 がオストワルド成長によるものであれば，分散柆子の体積 率 $V$ は一定であるため，強度変化山分散粒子径 $\mathrm{d}$ の0.5 乗 に比例して変化するはずである. 実祭ら 今回の結果では， $250^{\circ} \mathrm{C} \times 2 \mathrm{hr}$ 時效処理材を除くと, $02 \%$ 而力の変化と $\mathrm{Mg}_{2} \mathrm{Si}$ の直径の 0.5 乗の值の変化は，LMP を变数とする 1 次関数 により示寸ことが出来た. したがって， B 添加時效熱処理 材の強度変化は，十分時效処理時間が長い場合では，才ス トワルド成長による MgSi の形態恋化に起因寸ると考える ことができる. また， $250^{\circ} \mathrm{C} \times 2 \mathrm{hr}$ 熱処理材ては，時效処理 時間が非常に短いため，Mg2Si の析出が完了しておらず， 分散強化化加えて, Mg あるいは $\mathrm{Si}$ の固溶強化の寄与もあ るため, LMPのみでは説明できないのであろう.

最後に，B添加の有無による Al-Mg-Si 合金の時效処理中 の強度変化の違、について考察する. 図1に示したように B を含まないAl-Mg-Si 合金の強度変化は, LMP て整理した 場合，Al-Mg-Si 合金の変化と同じ傾きを有する直線で示す ことができた。この結果は，LMPが十分大きな値を有する 高温または長時間時効処理では， B の有無て関係なく，才 ストワルト成長による $\mathrm{Mg}_{2} \mathrm{Si}$ の形態変化のみ炕より説明で きることを意味している. 実際こ，長尾らはBを含有しな い場合の $\mathrm{Mg}_{2} \mathrm{Si}$ の形態変化をオストワルト成長と仮定する ことにより，時効処理時間と強度変化を定量的に説明可能 であることをすでこ示している゙. したがって, 図1で認め られたような $\mathrm{B}$ 添加による高温長時間時效処理時の強度変 化は，B添加により生じた化合物 $\mathrm{AlB}_{2}$ による分散強化の奇 与やMg, Si 以外の合金元素の含有量の違い による固溶また は析出強化といらた，時效処理前の強度変化によるものに 限定され，オストワルド成長による強度低下は， B 無添加 材と同様の理侖により説明できると考えることができる.

このことはこれまでこ報告されているAl-B 系状熊罒研究 (11)において、BはFCC-Al 中に固溶限をほとんど有さず、本 研究て対象としている様な $1 \mathrm{mass} \%$ B を添加したAl は室 温において、FOC-Al と $\mathrm{AB}_{2}$ の2相域に属するという事実 と整合する。すなわち、 $\mathrm{B}$ はAl と結合力か漒いため, $\mathrm{B}$ 添加しても，溶製時に化合物 $\mathrm{AlB}_{2}$ として晶出するため， $\mathrm{Al}$ 
の固溶は極めて小さく、 $\mathrm{Al}$ の結晶構造を変化させない， と考えることによって理解することができる.

\section{4. 钴}

$\mathrm{B}$ 添加した Al-Mg-Si 合金に対して, $230^{\circ} \mathrm{Cおよび} 250^{\circ} \mathrm{C}$ において, 最大 $10000 \mathrm{~h}$ までの恒温時効拠理を施した場合の 強度変化と $\mathrm{Mg}_{2} \mathrm{Si}$ の形態変化を調查した 得られた主な知 見は下記のとおりである.

(1) $230^{\circ} \mathrm{C}$ 保持の場合は $13 \mathrm{hr}$ 以上, $250^{\circ} \mathrm{C}$ 保持の場合、 $11 \mathrm{hr}$ 以上の時効処理を施した場合, $0.2 \%$ 耐力と引張強さの変化 はLMPの1 次関数として示すことが出来る.

(2) 時效熱処理中に，母相 $\mathrm{Al}$ の $4001>$ 方向に伸長した棒 状の $\beta$ '-Mg2

(3) $\beta^{\prime}-\mathrm{Mg}_{2} \mathrm{Si}$ の伸長方向に垂直な断面直径の-0.5 乗の值は LMPの 1 次関数として整理することができる.

(4) B 添加材の恒温長時間時効奺理による強度変化は, $\mathrm{Mg}_{2} \mathrm{Si}$ のオストワルド成長と Ashby の分散強化理論を用い ることにより説明することができる.

(5) 時効処理時の強度変化は B 無添加材とほほ同様の変 化を示す。これは添加したBが溶製時こ化合物 $\mathrm{AlB}_{2}$ として 晶出するため, $\mathrm{Mg}_{2} \mathrm{Si}$ の析出・成長挙動に大きな影響を及 ぼさないためであると考えられる。

\section{文献}

(1) Misumi, M., World Trend of Cask for Spent Nuclear Fuel, Nuclear Engineering, Vol. 38, No. 10 (1992), pp. 40-49.
(2) Shirai, T., et al., Dynamic Interaction between Spent Fuel Storage Cask and Reinforced Concrete Slab Subjected to Impact Load, Journal of the Atomic Energy Society of Japan, Vol. 37, No. 5 (1995), pp.430-441.

(3) Saegusa, T., et al., Trend of Dry Storage Technology of Spent Fuel, Journal of the Atomic Energy Society of Japan, Vol. 37, No. 8 (1995), pp.675-680.

(4) Rules on Transport / Storage Packagings for Spent Nuclear Fuel (2007), JSME S FA1-2007, Japanese Society of Mechanical Engineers

(5) Kajihara, K., et al., Development of Enriched Borated Aluminum Alloy for Basket Material of Cask for Spent Nuclear Fuel, Proceedings of the 10th International Conference on Nuclear Engineering, (ICONE10), No.22025 (2002), pp.1-8. ASME.

(6) Nagao, M., et al., Morphology Change of $\mathrm{Mg}_{2} \mathrm{Si}$ and Strength Change in a Load Isothermal Holding Test and a Long Continuous Cooling Test in Al-Mg-Si alloy, Journal of the Atomic Energy Society of Japan, Vol. 39, No. 3 (1997), pp.59-66.

(7) Bhadeshia, H.K.D.H., Honeycombe, R.W.K., Steels, Microstructure and Properties (3rd edition), (2006), p.197, Elsevier.

(8) Murayama, M., et al., The effect of $\mathrm{Cu}$ Additions on the Precipitation Kinetics in an Al-Mg-Si Alloy with Excess Si, Metallurgical and Materials Transactions $A$, Vol. 32A, No. 2 (2001), pp.239-246.

(9) Panseri, C. and Federighi, T., A Resistometric Study of Preprecipitation in an Aluminium-1.4\% $\mathrm{Mg}_{2} \mathrm{Si}$ Alloy, Journal Institute of Metals, Vol. 94 (1966), pp.99-107.

(10) Ashby, M.F., Work Hardening of Disparsionhardened Crystals, Philosophical Magazine, Vol. 14, (1966), pp.1157-1178.

(11) Deppish, C., Liu, G., Hall, A., Xu, Y., Zangvil, A., Shang, J. K., Economy, J., The Crystallization and Growth of $\mathrm{AlB}_{2}$ Single Crystal Flakes in Aluminium, Journal of Materials Research, Vol. 13, (1998), pp.3485-3498. 